\title{
THE EFFECT OF MORPHINE ON HUMAN NEUROMUSCULAR TRANSMISSION
}

\author{
P.C. Duke, C.H. Johns, C. Pinsky, And P. Goertzen
}

THE USE OF NARCOTIC ANALGESICS, such as morphine at moderate to high doses, is widespread in clinical anaesthesia. The narcotic is often given in combination with neuromuscular blocking agents. This has suggested to us that the effects of intravenous opiate narcotics on neuromuscular transmission should be considered in such circumstances. Bellville, Cohen and Hamilton reported that morphine, given intramuscularly in man at a dose of $10 \mathrm{mg}$ or less, did not add to the decrease in grip strength induced by subclinical doses of d-tubocurarine chloride. ${ }^{1}$ In contrast, animal studies indicate that morphine can significantly impair neurohumoral transmission both at peripheral muscarinic $^{2-4}$ and neuromuscular nicotinic sites. ${ }^{5-7}$ Frederickson and Pinsky have observed that morphine significantly decreases indirectly-elicited repetitive twitch responses in frog sciatic nervesartorius and rat phrenic nerve-hemidiaphragm preparations. ${ }^{5.6}$ They further demonstrated a decrease in the quantity of acetylcholine released per nerve impuise in the presence of morphine. ${ }^{6}$ In this present study we have examined the effects of a moderate dose of intravenous morphine on human neuromuscular transmission by observing its effects on mechanical twitch responses elicited by repetitive nerve stimulation.

\section{Merhods}

Subject material was divided into two separate groups, control and experimental. Control subjects, who did not receive morphine, consisted of five healthy young adult male volunteers. The experimental subjects were six healthy unpremedicated male patients of similar age slated for minor surgical procedures (e.g. dental extrac-

P.C. Duke, M.D., F.R.C.P.(C), Associate Professor, Department of Anaesthesia; C.H. Johns, M.D., Research Fellow. Department of Anaesthesia; C. Pinsky, B.Sc., M.Sc., Ph.D., Professor, Department of Pharmacology and Therapeutics; P. Goertzen, M.D. Anaesthesia Elective.

University of Manitoba Health Sciences Centre, General, A709-700 William Ave., Winnipeg, Manitoba, R3E 0Z3.

Reprint requests should be directed to Dr. P.C. Duke at the above address.

Canad. Anaesth. Soc. J., vol. 26, no. 3, May 1979 tions, nasal polypectomy). These subjects received infusions of morphine prior to neuromuscular testing, and oxygen by nasal catheter at $5 \mathrm{~L}$ per minute during the study. Alertness, and consequent minimization of respiratory depression in the morphine-infused subjects was deliberately encouraged by the experimenters. Both groups received intravenous infusions of five per cent dextrose in half-normal saline throughout the procedures. Neuromuscular testing in the morphine-infused group was done three hours before operation. All studies were performed in accordance with institutional policies on human experimentation.

All subjects had an ulnar nerve block at the elbow with $4 \mathrm{ml}$ of 0.25 per cent bupivicaine. This allowed us to perform high-frequency stimulation studies involving the wrist and hand without discomfort to the subject. The hand was stabilized in a modified Slomić frame ${ }^{8}$ and a brass ring was secured around the proximal phalanx of the thumb. This was attached to a Statham FT-10 force displacement transducer by a slender stainless steel wire, so that adduction of the thumb following ulnar nerve stimulation was $90^{\circ}$ to the transducer. The thumb was preloaded to a tension of 350 to $400 \mathrm{gm}$ and the transduced signal was recorded on a 4-channel Hewlett-Packard recorder (model \#7784A). Steel needle electrodes were placed subcutaneously $2.5 \mathrm{~cm}$ apart at the wrist and connected by flexible leads to a timing mechanism which controlled two Grass SD-9 stimulators. The timing mechanism was based on a motor-driven sequence programmer and triggered by a delayed logic circuit. This system allowed us to produce accurately the desired sequence of stimuli and to turn the nerve stimulators off and on at the appropriate time. Both stimulators were set to deliver monophasic stimuli of 0.1 msec duration at supramaximal voltage; one was driven to deliver single stimuli at $0.2 \mathrm{hz}$ (i.e. 1 per 5 seconds) and the other to deliver tetanic trains at frequencies of either 50 , 100 , or $200 \mathrm{hz}$. The timer was programmed to deliver a five-second tetanic train preceded and followed by a 30-second period of single stimuli at $0.2 \mathrm{hz}$. This 65 -second cycle of stimulation was applied continuously. Studies at the three tetanic 201 


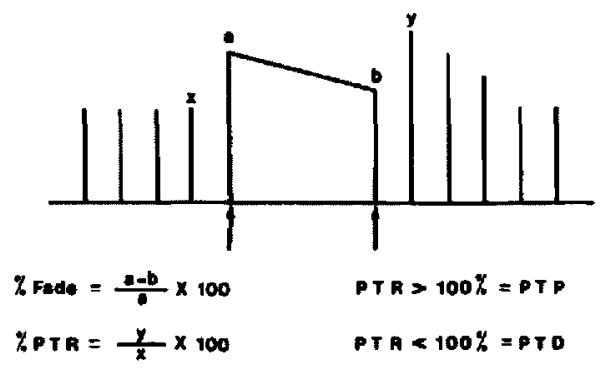

Figure 1 Calculations of per cent fade and posttetanic response (see text).

frequencies were repeated sequentially over an experimental test period of approximately 60 minutes. Slight variations occurred in this time period because a sufficient period of time (usually two to four minutes) was allowed for twitch height to return to pretetanic control levels before commencing each subsequent tetanizing stimulus. In control subjects there were from three to four sequences of testing at the three tetanic frequencies in every 15-minute period; in the morphine-infused group these were from two to three such sequences over 15 minutes. A 15 minute control period of such measurement preceded the infusion of morphine in the druginfused experimental group. Morphine sulphate was infused intravenously $0.5 \mathrm{mg} \cdot \mathrm{kg}^{-1}$ over four minutes at the end of the control measurements; the stimulation sequence was continued thereafter for 60 minutes.

Tetanic fade, post-tetanic facilitation (PTF) and post-tetanic depression (PTD) were calculated by the method of Epstein, et al.,9 utilizing the formulae shown in Figure 1. With reference to that figure, tetanic fade was calculated as the percentage difference between the initial (a) and final (b) twitch tension during the five-second tetanus. The post-tetanic response (PTR) was calculated as the percentage of the first posttetanic twitch height $(y)$ to the last pretetanic twitch height ( $\mathrm{x}$ ). A value of PTR of less than 100 per cent represents post-tetanic depression (PTD), and one greater than 100 per cent represents post-tetanic potentiation (PTP).

The 60-minute study period was divided into 15-minute intervals and mean values for fade and PTR were calculated at each tetanic frequency employed in such intervals. Statistical inferences are based on Student's unpaired I-test, with probability values of less than 0.05 held as significant.

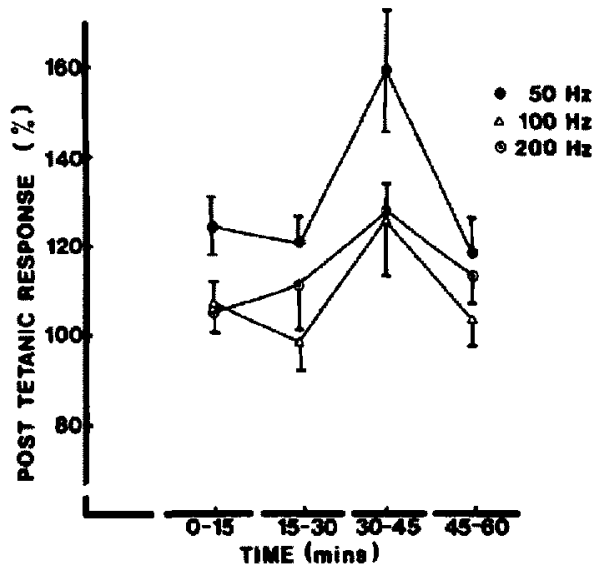

FIGURE 2 Mean post-tetanic response ( \pm S.E.M.) of five control subjects at three tetanizing frequencies. Only during the $50 \mathrm{~Hz}$ tetanus studies was there a significant difference during the $30-45$ minute perjod when compared to the other three time periods.

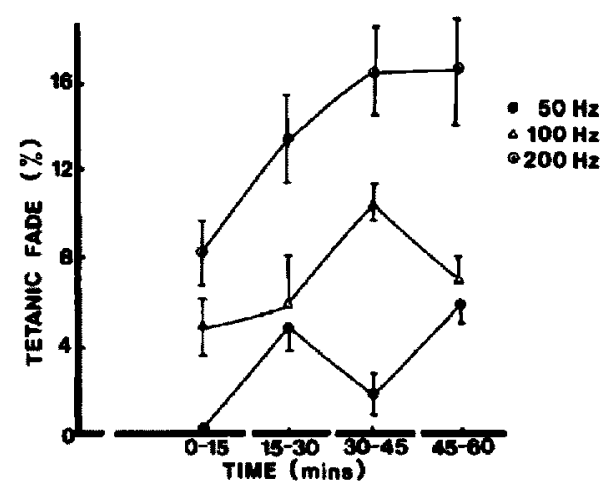

FIGURE 3 Mean tetanic fade ( \pm S.E.M.) of five control subjects during three tetanizing frequencies over a one-hour period. A statistical significant increase in fade occurred only at $200 \mathrm{~Hz}$ tetanus during the last 30 minutes.

\section{RESULTS}

\section{Control subjects}

Control twitch heights ranged from $0.6 \mathrm{~kg}$ to $1.8 \mathrm{~kg}$ in both groups of subjects, while mean control tetanic tensions ranged from $4.7 \mathrm{~kg}$ to $7.2 \mathrm{~kg}$. This is well within the range of expected values for subjects tested in the fashion described here. ${ }^{9}$ Values for the post-tetanic responses and tetanic fade in the five control subjects are shown in Figures 2 and 3. PTR values at all three tetanizing frequencies were greater than 100 per 


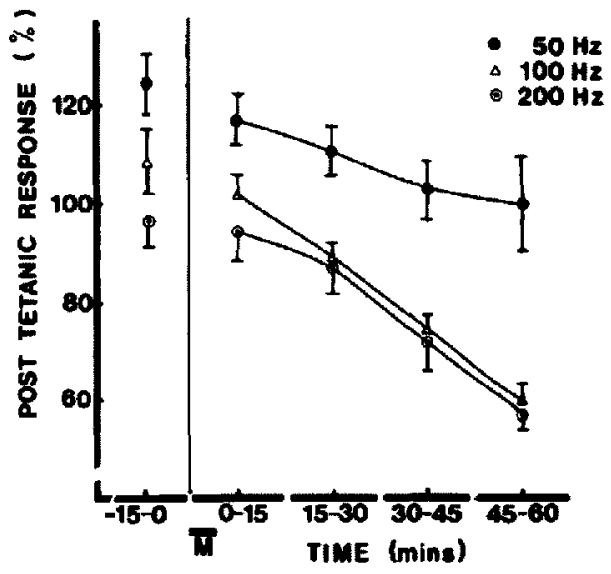

Figure 4 Mean post-tetanic response ( $\pm S$.E.M.) for six subjects 15 minutes before and 60 minutes after morphine infusion (M). Values obtained 15 to $60 \mathrm{~min}$ utes after mor phine infusion were significantly different from those obtained during the preceding control. P.T.D. increased significantly with time after morphine infusion at all three frequencies. This was most marked at 100 and $200 \mathrm{~Hz}$ tetanus.

cent throughout the 60 minute test period (Figure 2). There were no significant differences between PTR values obtained during the first 30 minutes and those obtained over the last 15 minutes (Figure 2). PTR values were highest during the 30 to 45 minute period, but a significant difference occurred only with $50 \mathrm{hz}$ stimulation. Regression analysis (with $n=5$ ) gave these correlation coefficients (R) and slopes (b); at tetanizing frequency $50 \mathrm{hz} R=0.17, b=0.16$; at $100 \mathrm{hz} R=$ $0.15, b=0.09$ and at $200 \mathrm{hz} R=0.21, b=0.07$.

There was a slight tendency for tetanic fade to increase during the experiment at all frequencies (Figure 3$). R$ values $(n=5)$ obtained at 50,100 and $200 \mathrm{hz}$ were $0.74,0.64$ and 0.93 respectively, with associated slopes of $0.11,0.08$ and 0.18 . When comparing fade values obtained in the last 30 minutes to those obtained during the first 15 minutes, only at $200 \mathrm{hz}$ was there a significant difference.

\section{Morphine-infused subjects}

Throughout the 60 minute post-infusion test period subjects remained alert, conversed with the experimenters, and showed no clinical signs of respiratory depression. Post-tetanic responses during the first 15 minutes after morphine infusion were not different from preinfusion controls for all three tetanizing frequencies (Figure 4).

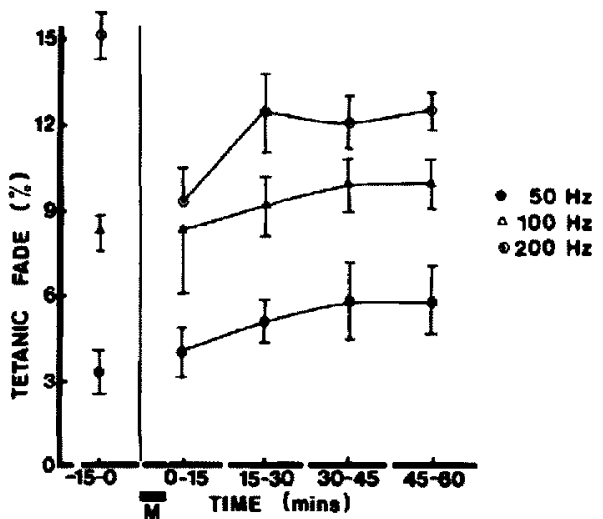

Figure 5 Mean tetanic fade $( \pm$ S.E.M.) for six subjects before and after morphine infusion (M). Only at $200 \mathrm{~Hz}$ tetanus was there a significant difference before and after morphine infusion.

PTD increased significantly from I5 to 30 minutes after morphine infusion until the experiment was terminated. At any given tetanizing frequency, mean PTR values obtained during the last 30 minutes of the experiments were significantly lower than those in the two previous 15 -minute intervals (Figure 4). The relationship of response with time were almost identical for 100 and $200 \mathrm{hz}$ (Figure 4). Analysis of regression for PTR with time at all tetanizing frequencies over the 60 minute period after morphine infusion yielded $R$ (with $n=6$ ) values of -0.99 at all frequencies. Slope values for 50,100 and $200 \mathrm{hz}$ were -0.40 , -0.90 and -0.83 respectively.

Pre-morphine control tetanic fade values were not significantly different from values after morphine infusion for 50 and $100 \mathrm{hz}$ tetanus (Figure 5). Only at $200 \mathrm{hz}$ was the control significantly different from any of the post-morphine values. There was a general tsend for all fade values to increase with time after morphine infusion, although this trend was not statistically significant. Correlation coefficients and slopes $(n=6)$ at the tetanizing frequencies were $50 \mathrm{hz}, 0.91$ and 0.04 : at $100 \mathrm{hz}, 0.94$ and 0.03 : and $200 \mathrm{hz}, 0.77$ and 0.06 .

\section{Discussion}

The post-tetanic twitch response in morphine-infused subjects diminished significantly with time after infusion (Figure 4). There was no corresponding diminution with time after initial measurement in the untreated control subjects. In fact, post-tetanic potentiation in control 
subjects tended to increase with time after the initial measurements, with statistical significance being achieved only with the $50 \mathrm{hz}$ tetanizing frequency (Figure 2). Hence morphine administration, in the dosage and by the route used in this study, can be seen to diminish the post-tetanic phase of neuromuscular transmission. The observed impairment of PTR is not likely due to hypercarbia or hypoxia, because of the precautions taken here to avoid those difficulties.

Frederickson has suggested a mechanism of action which explains the impairment by morphine of acetylcholine release at the rat skeletal neuromuscular junction. ${ }^{10} \mathrm{He}$ has provided evidence to show that morphine acts at some intraterminal site to block the mobilization from bound stores of the neurotransmitter in the nerve terminal to the readily releasable fraction therein. Such a mechanism could explain the post-tetanic depression seen with morphine in the present human study. The tetanizing stimulus would, presumably, exhaust the readily releasable fraction therein. This could explain the post-tetanic depression seen with morphine in the present human study. The tetanizing stimulus would, presumably, exhaust the readily releasable pool of acetylcholine which then cannot be replenished from bound stores in the presence of morphine. This mechanism predicts an increasing effect of the drug with an increase in tetanizing frequency. Such a relationship is demonstrated in Figure 4. In other studies in this laboratory we have observed that plasma levels of morphine, administered intravenously in the manner described here, will have reached a low asymptotic level at one hour after infusion (Duke and Mitenko, unpublished). Morphine-induced PTD, however, had increased in the last 15 minute post-infusion interval (45-60 minutes; Figure 4). These observations are in accord with the suggestions of intraterminal site of action to explain the morphine-induced PTD since sequestration of the drug within nerve terminals would permit its continued action there even after plasma levels had diminished.

Bell and Reese have suggested that the effects of morphine at the neuromuscular junction should be considered as "nonspecific" because they are difficult to block with the essentially "pure" narcotic antagonist naloxone." This is true, however, only when a post-synaptic response, such as muscular contraction, is used as the measure of neuromuscular transmission. In studies on the release of radiolabelled acetylcholine, Frederickson has demonstrated an un- mistakable naloxone antagonism of morphineinduced impairment of acetylcholine release in the rat phrenic nerve-hemidiaphragm preparation. ${ }^{10}$ The antagonism is not observed postsynaptically, because naloxone has a significant curare-like action at concentrations required to block the presynaptic effects of morphine. ${ }^{10}$ Hence we anticipated inability of naloxone hydrochloride, $0.2-0.4 \mathrm{mg}$ intravenously to block the morphine-induced depression of PTR in these studies; this was abserved in two subjects from the morphine-infused group. It is obvious, however, that the apparent absence of naloxone antagonism does not alter the need to consider the clinical implications of reproducible morphine effects at the skeletal neuromuscular junction.

The clinician often encounters patients with diseases that manifest abnormalities of neuromuscular transmission. Among these are included myaesthenia gravis, the myaesthenic syndrome and muscular dystrophies. In such patients, where neuromuscular transmission is already compromised, it is possible that morphine and other opiate narcolics may add a peripheral component to the respiratory effects of these drugs.

\section{SUMmaRY}

By utilizing high frequency nerve stimulation, we observed the effects of morphine sulphate, 0.5 $\mathrm{mg} \cdot \mathrm{kg}^{-1}$ on human neuromuscular transmission. Tetanic fade at 50,100 and $200 \mathrm{hz}$ did not change during the one hour period after infusion of morphine. Post-tetanic depression (PTD) of single twitch response increased progressively with time over the one-hour study period. This was most marked with the 100 and $200 \mathrm{hz}$ tetanic frequencies. In contrast, control subjects displayed either no change, or a slight increase (post-tetanic facilitation; PTF), over a similar one-hour test period. We believe these results are best explained by a presynaptic action of morphine, whereby intraterminal mobilization of acetylcholine is impaired by the opiate narcotic drug.

\section{RÉSUME}

A l'aide de stimulus nerveux à fréquences élevées, nous avons étudié les effets d'une dose de $0.5 \mathrm{mg} \cdot \mathrm{kg}^{-1}$ de sulfate de morphine sur la transmission neuromusculaire de l'homme. L'épuisement tétanique à 50,100 et $200 \mathrm{~Hz}$ n'a pas changé dans l'heure qui a suivi l'injection de morphine. Dans la même période, nous avons 
observé que la diminution de la réponse à un stimulus unique après tétanisation devenait plus marquée avec le passage du temps; le phénomène était plus intense avec des fréquences de 100 et $200 \mathrm{~Hz}$.

D'autre part, on n'a pas observé de changements ou, tout au plus, a-t-on noté une légère augmentation de la facilitation post-tétanique chez les sujjets contrôles.

Nous croyons que ces résultats seraient explicables par une activité présynaptique de la morphine, qui gênerait la mobilisation de l'acétylcholine aux terminus nerveux.

\section{ACKNOWLEDGEMENTS}

This work was supported by grants from the Medical Research Council of Canada.

The authors wish to thank Mr. Wayne Pucci and Mrs. S. Trosky for their technical assistance.

\section{REFERENCES}

I. Bellville, J.W., Cohen, E. N., \& Hamilton, J. The interaction of morphine and d-tubocurarine on respiration and grip strength in man. Clin. Pharmacol. \& Therap. S: 35 (1963)

2. PATON, W.D.M. The action of morphine and related substances on contraction and an acetylcholine output of coaxially stimulated guinea-pig ileum, Brit. J. Pharmacol. 12: 119 (1957).
3. Cox, B.M. Weinstock, M. The effect of analgesic drugs on the release of acetylcholine from electrically stimulated guinea-pig ileum. Br. J. Pharmac. Chemother. 27: 81 (1966).

4. Grang, E.A. \& Kosterlitz, H.W. Agonist and antagonist action of morphine-like drugs on the guinea-pig isolated ileum. Br. J. Pharmac. Chemother. 27: 514(1966).

5. Frederickson, R.C.A. \& Pinsky, C. Morphine and nalorphine impair neuromuscular transmission. Nature New Biol. 231: 94 (1971)

6. Pinsky, C. \& Frederickson, R.C.A. Morphine impairs acetylcholine release but facilitates acetyl. choline action at a skeletal neuromuscular junction. Nature New Biol. 231 : 93 (1971).

7. Soteropoulos, G.C. \& StANDAERT, F.G. Neuromuscular effect of morphine and naloxone. J. of Pharmacol. \& Exp. Therap. 184: 136 (1973).

8. Slomić, A., Rosenfalck, A., \& Buchthal, F Electrical and mechanical responses of normal and myasthenic muscle. Brain Research 10: I (1968).

9. Epstein, R.A. \& Epstein, R.M. The electromyogram and the technical response of indirectly stimulated muscle in anesthetized man following curarization. Anesthesiology 38: 212 (1973)

10. Frederickson, R.C.A. Actions of morphine on cholinergic transmission - importance in opiate narcotic dependence. Ph.D. Thesis, University of Manitoba (1972).

11. BeLL, K.M. \& Reese, J.M.H. The depressant action of morphine on transmission at a skeletal neuromuscular junction is non-specific. J. Pharm. Pharmac. 26: 686 (1974), 